\title{
Concurrent intracranial malignant triton tumor and relapsed pituitary adenoma in the sellar region: a case report and review of the literature
}

bin liu ( $\sim$ binliu@email.sdu.edu.cn )

Shandong First Medical University

Jinchao Wang

Shandong First Medical University

shangchen $\mathrm{xu}$

Shandong First Medical University

\section{Case Report}

Keywords: Malignant triton tumors, Sellar region, Radiation, Concurrent tumor

Posted Date: February 21st, 2022

DOI: https://doi.org/10.21203/rs.3.rs-1374805/v1

License: (c) (i) This work is licensed under a Creative Commons Attribution 4.0 International License.

Read Full License 


\section{Abstract}

Background: Malignant triton tumor (MTT) is a rare kind of malignant peripheral nerve sheath tumors, histologically characterized by rhabdomyoblastic differentiation. There are limited reports of MTT occurring in the intracranial area. The treatment modality consisting of total surgical resection plus postoperative radiotherapy is generally accepted. However, even with optimal treatment, most patients will die within a few months.

Case presentation: We report a 71-year-old man with a history of pituitary adenoma, who underwent surgical treatment and postoperative gamma knife therapy. Magnetic resonance imaging (MRI) of the brain revealed a mass with two distinctive components in the sellar area. Postoperative pathology found that the lesion is consisted of a MTT and a relapsed pituitary adenoma.

Conclusions: The present case is the first report of MTT that occurred in the sellar area. It is also the first case of intracranial MTT with other concurrent tumors (relapsed pituitary tumors). Meanwhile, this case has a clear history of radiation, suggesting that the occurrence of MTT may be related to radiation.

\section{Introduction}

MTT is a rare subgroup of MPNSTs, which is histologically defined basing on rhabdomyoblastic differentiation. They mimic other brain tumors on MRI, which brings challenges to preoperative diagnosis. MTTs arising from the cerebellopontine angle, lateral ventricle, parietooccipital, nasal cavity-cribriform plate, bifrontal, middle cranial fossa and right frontal regions have been reported sporadically [1-11]. However, this the first MTT case reported with concomitant pituitary adenoma in the saddle area.

\section{Case Report}

\section{History and presentation}

A 71-year-old man was referred to our hospital with impaired vision and intermittent nausea and vomiting for 20 days. He had a history of nausea and vomiting 10 years ago. MRI revealed a lesion in the sellar region in a local hospital. He underwent gross total surgical resection and pathologic examination confirmed the lesion as a pituitary adenoma. Subsequently, he underwent adjuvant gamma knife treatment. Thereafter, the symptoms disappeared, except that he experienced hyponatremia several times without formal treatment. Twenty days ago, the patient experienced vision loss, and recurred intermittent nausea and vomiting. The local hospital diagnosed cataract and a cataract surgery was performed accordingly. After the cataract surgery, the vision recovery was not ideal and continued to worsen. Meanwhile, intermittent nausea and vomiting did not alleviate. Intracranial MRI revealed an irregular mass with 2 distinctive components in sellar area (Figure 1a-b). Combined with medical history, it is considered that the tumor recurred. The patient was then referred to our hospital and underwent partial resection of the lesion with a transnasal transsphenoidal approach. 
Pathological findings revealed that the tumor is composed of pituitary adenoma in the upper area and a concurrent MTT in the lower area with a clear border (Figure 2). In the MTT component, immunostaining was positive for Desmin, Myogenin, MyoD1, TTF-1, Syn, CK, Ki-67 staining (MIB labeling index) was 10$60 \%$ (Fig. 2C-i). On the fourth day after the operation, computer tomography (CT) examination of the brain revealed that the tumor mass containing MTT component in sphenoidal sinus was gross totally resected, while the pituitary adenoma was partially resected with residual tumor in the suprasellar area (Figure 1cd). Post-operatively, the patient developed hyponatremia and recovered after active treatment. The patient's vision loss also recovered well after the operation. However, blurred vision recurred and continued to worsen 7 days after the operation. A re-examination of cranial MRI 56 days after the operation showed that the residual tumor had grown again. (Figure 1e-f). The patient has been blind and refused a second operation. Eventually, he died 64 days after operation.

Table 1

Summary of reports of intracranial malignant triton tumors (MTTs)

\begin{tabular}{|c|c|c|c|c|c|c|c|}
\hline & $\begin{array}{l}\text { Age } \\
\text { (v) }\end{array}$ & Sex & $\begin{array}{l}\text { NF- } \\
1\end{array}$ & $\begin{array}{l}\text { Previous } \\
\text { radiation }\end{array}$ & Site of MTT & $\begin{array}{l}\text { Merge } \\
\text { other } \\
\text { tumors }\end{array}$ & $\begin{array}{l}\text { Myoglobin } \\
\text { or desmin }\end{array}$ \\
\hline Best, 1987 [1] & 24 & $\mathrm{~F}$ & No & No & $\begin{array}{l}\text { Cerebellopontine } \\
\text { angle }\end{array}$ & No & Yes \\
\hline Han et al., 1992 [2] & 47 & $\mathrm{~F}$ & No & No & $\begin{array}{l}\text { Cerebellopontine } \\
\text { angle }\end{array}$ & No & Yes \\
\hline $\begin{array}{l}\text { Comey et al., } 1998 \\
\text { [3] }\end{array}$ & 44 & $M$ & No & Yes & $\begin{array}{l}\text { Cerebellopontine } \\
\text { angle }\end{array}$ & No & Yes \\
\hline $\begin{array}{l}\text { De Cauwer et al., } \\
2000 \text { [4] }\end{array}$ & 57 & M & Yes & No & Lateral ventricle & No & Yes \\
\hline $\begin{array}{l}\text { Bornstein-Quevedo } \\
\text { et al., } 2003 \text { [5] }\end{array}$ & 3 & M & No & No & Parietooccipital & No & Yes \\
\hline $\begin{array}{l}\text { De Cauwer et al., } \\
2007 \text { [6] }\end{array}$ & 57 & $M$ & No & No & $\begin{array}{l}\text { Cerebellopontine } \\
\text { angle }\end{array}$ & No & Yes \\
\hline Lau et al., 2010 [7] & 42 & M & No & No & $\begin{array}{l}\text { Nasal cavity - } \\
\text { cribriform plate }\end{array}$ & No & Yes \\
\hline Gong et al., 2012 [8] & 55 & $\mathrm{~F}$ & No & No & $\begin{array}{l}\text { Cerebellopontine } \\
\text { angle }\end{array}$ & No & Yes \\
\hline Smith et al., 2014 [9] & 26 & M & Yes & No & Bifrontal & No & Yes \\
\hline Eros et al., 2018 [10] & 74 & $\mathrm{~F}$ & No & Yes & $\begin{array}{l}\text { Middle cranial } \\
\text { fossa }\end{array}$ & No & Yes \\
\hline $\begin{array}{l}\text { Adriano et al., } 2019 \\
\text { [11] }\end{array}$ & 5 & $\mathrm{~F}$ & Yes & unknown & Right frontal & No & Yes \\
\hline The present case & 71 & M & Yes & Yes & Sellar region & Yes & Yes \\
\hline
\end{tabular}




\section{Discussion}

MPNSTs are exceptionally rare tumors, occurring at an incidence rate of $0.001 \%$ within the general population[12]. Despite of the rarity of MTT, 11 intracranial cases have been reported, which is summarized in Table 1. However, to the best of our knowledge, the present case is the first report of MTT in sellar region with a clear history of radiation and a concurrent relapsed pituitary adenoma.

The most charcteristic feature of MTT is the presence of rhabdominal muscle. In 1938, Masson and Martin first described this compound tumor. They proposed that this tumor induces skeletal muscle differentiation in the same way as normal nerves[13]. It got the name as malignant salamander tumor in 1973 , basing on previous observations that if the sciatic nerve was implanted into the dorsal side, the salamander would produce redundant limbs composed of striated muscle, bone and nerve tissue [14]. Nevertheless, it is still unclear from which cell the tumor originated [15]. It is generally believed that the striated muscle cells in tumors are induced by or directly transformed from Schwann cells [5]. In the present case, the visual acuity of the patient recovered completely after operation and the MTT component located apart from the optic nerve, which can basically exclude the origination of MTT from the optic nerve sheath. Because TTF-1 can be diffusely expressed in a common pituitary cell lineage (such as non-neoplastic pituitary, pituitary tumor, spindle cell tumor and granulosa cell tumor)(Figure $2 \mathrm{~h}$ ) [16], we boldly speculate that the tumor cells of this case might derived from neurohypophysis.

MTTs, a subgroup of MPNST, are reported to exhibit rhabdomyosarcoma-like differentiation and follow a particularly aggressive course. MTT mimic gliomas on MRI [17], where both of them show irregular masses, fuzzy boundaries, a peripheral increase, a low or equal signal on T1, and a high signal on T2 images [6]. Genomic and proteomic studies have begun to reveal the complexity of chromosome and transcriptional changes behind these tumors, but reliable cytogenetic markers have not been established to distinguish MTT and MPNST and/or explain the obvious differences in their behavior [18-21]. Woodruff et al. proposed three criteria to determine whether a tumor can really be classified as a MTT [22]: 1) The first criterion is the origin from a peripheral nerve, or in a patient with NF-1, or in a location typical for peripheral nerve tumors, or represents a metastasis from such tumor; 2) The second criterion is the growth characteristics of the Schwann cells; 3) The third criterion is the inclusion of rhabdomyoma cells which must exclude the expansion or metastasis of exogenous rhabdomyosarcoma. Daimaru et al. later proposed to expand the range to include the following [23]: 1) The first criterion is that it is shown as a malignant schwannoma under the microscope and contains focal rhabdomyoblasts; The second criterion is that, the tumor is mainly composed of striated muscle and focal Schwann cells, which are found in neuropathy or NF-1 expression. Now, the diagnosis of MTT is commonly depended on these criterias and on immunohistochemical findings [24].

The differential diagnosis of MTT includes other spindle cell malignant tumors, such as fibrosarcoma, synovial monophase sarcoma, leiomyosarcoma, low-grade fibroblast sarcoma, especially spindle cell rhabdomyosarcoma [25]. Low-grade myofibroblastic sarcomas, synovial sarcomas, and fibrosarcomas do not contain rhabdomyoblasts and do not respond to skeletal muscle staining such as desmin. Since 
spindle cell rhabdomyosarcoma combines spindle cells and rhabdomyoblasts, logically, this is the most difficult differential diagnosis of MTT. Rhabdomyosarcoma, especially embryonic rhabdomyosarcoma, is mainly consisted of undifferentiated round cells and spindle cells. It is worth noting that highly differentiated rhabdomyosarcoma cells have strong eosinophilic cytoplasm and are easy to be misdiagnosed as MTT. However, the composition of rhabdomyosarcoma is different from that of MTT, and the mean age of patients with rhabdomyosarcoma is younger than that of patients with MTTs. In addition, a characteristic of diagnostic value is that there are usually high-density cell areas surrounding blood vessels, alternating with parvicellular areas rich in mucosal intercellular material. In the present case, immunostainings were positive for skeletal muscle markers including myogenin, desmin, myod1, synaptophysin, and CK, which supports the diagnosis.

Mean age of patients with MTT at diagnosis was 39 years, and most patients were males (6/9). Distant metastasis accounted for about one third, local progression or recurrence rate accounted for $50 \%$, and the median time of recurrence/progression was 6 months, respectively [26]. In previous reports, head and neck MTTs seemed to have a benign prognosis, but recent studies did not support this conclusion [27]. The 5-year survival rate of patients with MTT was $11-14 \%$, which was significantly lower than that of patients with MPNST (34-52\%)[24-26]. The adverse prognostic factors of MTTS mainly include NF-1, age, size, surgical method, positive surgical margin, early local recurrence and the location of the tumor in the trunk[28-29]. Unfortunately, our patient has many unfavorable prognostic factors identified in the literature: tumor larger than $1.5 \mathrm{~cm}, \mathrm{NF} 1$ immunoreactivity and early local recurrence.

It is reported that $8 \%$ of patients with MTT had been exposed to radiation [27], which is recognized as a risk factor [26]. In addition, even therapeutic radiation can trigger the formation of MTT. For instance, there are several reports of malignant progression of benign schwannoma to MTT after therapeutic radiation $[3,29]$. In a previous intracranial MTT case [3], the patient's condition was relieved after the same gamma knife therapy, but his condition also progressed rapidly and died within a year. Our report also provides evidence that the occurrence of MTT might be induced by radiation therapy.

Since MTT is rare and lack of prospective clinical trials, there is no standard treatment available. Complete resection can improve the prognosis, reduce the risk of local recurrence and metastasis, and improve the efficacy of adjuvant therapy. Analysis of 124 patients with MTT showed that adjuvant radiation therapy reduces the risk of death, but is not associated with a reduction in progression or recurrence [26]. At present, it is generally believed that subtotal cytoreductive surgery cannot improve the survival rate of MTT patients [24]. Main factors affecting survival appear to be the location of the tumor and the excision extent. Although adjuvant chemotherapy has not been proved to be effective [26], there are certain evidence that patients who respond to neoadjuvant chemotherapy should also receive adjuvant therapy immediately [30]. However, most MTT patients usually die within a few months, even after receiving optimal treatments[31].

In the future, we hope to have more cases and studies to better understand this tumor and provide more reliable diagnostic methods, especially pathological diagnostic criteria and more effective treatment 
strategies.

\section{Conclusion}

In summary, to our knowledge, this is the first report of MTT in sellar region and with concurrent other tumors. This case underwent radiation after the first operation, which suggests that the occurrence of MTT might be caused by radiation. The patient received partial resection of the lesion with a transnasal transsphenoidal approach. The patient did not receive any adjuvant treatment postoperatively. Eventually, he died 64 days after the operation. Unfortunately, due to the rapid progress of the patient's condition, this case did not have much value for reference in treatment. In the future, we hope to have more cases and studies to better understand this tumor and provide more reliable diagnostic methods, especially pathological diagnostic criteria and more effective treatment strategies.

\section{Abbreviations}

\begin{tabular}{|ll|}
\hline MTT & Malignant triton tumor \\
\hline MRI & magnetic resonance imaging \\
\hline MPNSTs & malignant peripheral nerve sheath tumors \\
\hline TTF-1 & Thyroid transcription factor- 1 \\
\hline Syn & synaptophysin \\
\hline CK & cytokeratin \\
\hline CT & computer tomography \\
\hline PA & pituitary adenoma \\
\hline HE & Hematoxylin and eosin \\
\hline
\end{tabular}

\section{Declarations}

Ethical approval

This is under compliance with institutional review board guidelines and approval IRB protocol number SWYX2021-514. Also, it was in accordance with the Helsinki Declaration.

\section{Consent for publication}

The patient provided written informed consent for publication of this case report. 


\section{Availability of data and materials}

Not applicable

\section{Conflicts of interest}

The authors declare no potential conflicts of interest in relation to this article.

\section{Funding}

This study was supported by National Natural Science Foundation of China (no. 81902531).

\section{Author contributions}

JCW analyzed and interpreted the data, and wrote the manuscript. SCX analyzed and interpreted the data, and revised the manuscript. BL designed and conceptualized the study, interpreted the data, and revised the manuscript.

\section{Acknowledgements}

The authors would like to thank our patient for allowing for his case to be presented.

\section{References}

1. Best PVJAN. Malignant triton tumour in the cerebellopontine angle. Report of a case. 1987;74(1):92.

2. Han DH, Dong GK, Chi JG, Park SH, Kim YGJJoN. Malignant triton tumor of the acoustic nerve. Case report. 1992;76(5):874-877.

3. Comey CH, Mclaughlin MR, Jho HD, Martinez AJ, Lunsford LDJJoN. Death from a malignant cerebellopontine angle triton tumor despite stereotactic radiosurgery. Case report. 1998;89(4):653658.

4. Takahashi Y, Sugita Y, Abe T, Yuge T, Tokutomi T, Shigemori MJAN. Intraventricular malignant triton tumour. 2000;142(4):473-477.

5. Bornstein-Quevedo L, Peralta-Olvera F, Marhx-Bracho A, Rodríguez-Jurado R, Leon-Bojorge BDJP, Pathology D. Cerebral malignant nerve sheath tumor, triton tumor variant: case report. 2003;6(2):168172.

6. Cauwer HD, Bogers JP, Duwel V, Hauwe VD, Croese P, Marck EVJJoN. An intracerebral intraparenchymatous triton tumor in a man with neurofibromatosis. 2007;254(8):1009-1011. 
7. Lau OD, Nabili V, Chi L, Kirsch C, Abemayor EJAoo-h, surgery n. Pathology quiz case 1. Diagnosis: Sinonasal malignant Triton tumor (MTT) with intracranial extension. 2010;136(9):929, 931.

8. Gong $L$, Liu $X Y$, Zhang WD, et al. A rare case of malignant triton tumor in the cerebellopontine angle. 2012;7(1):1-4.

9. Smith RE, Kebriaei MA, Gard AP, Mccomb RD, Lennarson PJJBTP. Intracranial malignant triton tumor in a patient with neurofibromatosis type 1: Case report and review of the literature. 2014;31(2).

10. Eros, Bruzzone, llaria, et al. Arare case of intracranial malignant triton tumor arising in the middle cranial fossa: acase report and review of the literature. 2018.

11. Basso A, Dias, Eduardo, et al. Teaching Neurolmages: Intracranial malignant triton tumor: An uncommon location of a rare tumor. 2019.

12. Ducatman BS, Scheithauer BW, Piepgras DG, Reiman HM, Ilstrup DMJC. Malignant peripheral nerve sheath tumors. A clinicopathologic study of 120 cases. 1986;57(10):2006.

13. Weiss SW, Goldblum JR. Malignant tumors of peripheral nerves; In Weiss SW, Goldblum JR (eds): Enzinger and Weiss's Soft Tissue Tumors. 2008.

14. Locatelli PJeRT. Formation de Membres Surnumeraires. C. R. Assoc des Anatomistes. 1925;1.

15. Barnard ZR, Agarwalla PK, Jeyaretna DS, et al. Sporadic primary malignant intracerebral nerve sheath tumors: case report and literature review. 2011;104(2):605-610.

16. Mete O, Lopes MB, Asa SLJAJoSP. Spindle Cell Oncocytomas and Granular Cell Tumors of the Pituitary Are Variants of Pituicytoma. 2013;37(11):1694-1699.

17. Jouhilahti EM, Peltonen S, Heape AM, Peltonen J. The pathoetiology of neurofibromatosis 1. Am J Pathol.2011;178(5):1932-1939.

18. Grobmyer SR, Reith JD, Shahlaee A, Bush $\mathrm{CH}$, Hochwald SNJJoSO. Malignant peripheral nerve sheath tumor: Molecular pathogenesis and current management considerations. 2008;97.

19. Velagaleti G, Miettinen M, Gatalica ZJCGC. Malignant peripheral nerve sheath tumor with rhabdomyoblastic differentiation (malignant triton tumor) with balanced $t(7 ; 9)(q 11.2 ; p 24)$ and unbalanced translocation $\operatorname{der}(16) t(1 ; 16)(q 23 ; q 13)$. 2004;149(1):23-27.

20. Acquisition of $\mathrm{i}(8 \mathrm{q})$ as an early event in malignant triton tumors \% J Cancer Genet Cytogenet. 2004;154(2):150-155.

21. Jr BR, Bridge JA, Neff JR, Naumann S, Althof P, Bruch LAJJoCP. Recurrent chromosomal imbalances and structurally abnormal breakpoints within complex karyotypes of malignant peripheral nerve sheath tumour and malignant triton tumour: a cytogenetic and molecular cytogenetic study. 2004;57(11):1172.

22. Millett WB, Woodruff TJ, Smith RM, Foote W, Chernik NLJc. Peripheral nerve tumors with rhabdomyosarcomatous differentiation (malignant "Triton" tumors). 1973;32(2):426.

23. Daimaru Y, Hashimoto H, Enjoji MMJHP. Malignant "triton" tumors: A clinicopathologic and immunohistochemical study of nine cases. 1984;15(8):768-778. 
24. Stasik CJ, Tawfik OJAoP, Medicine L. Malignant peripheral nerve sheath tumor with rhabdomyosarcomatous differentiation (malignant triton tumor). 2006;130(12):1878-1881.

25. Mentzel T, Kuhnen CJVA. Spindle cell rhabdomyosarcoma in adults: clinicopathological and immunohistochemical analysis of seven new cases. 2006;449(5):554-560.

26. Mcconnell YJ, FRCSC, Giacomantonio CA, Oncology MJJoS. Malignant triton tumors-complete surgical resection and adjuvant radiotherapy associated with improved survivalt. 2012.

27. Terzic A, Bode B, Gratz KW, Stoeckli SJ. Prognostic factors for the malignant triton tumor of the head and neck. Head Neck.2009;31(5):679-688.

28. Kamran SC, Howard SA, Shinagare AB, et al. Malignant peripheral nerve sheath tumors: Prognostic impact of rhabdomyoblastic differentiation (malignant triton tumors), neurofibromatosis 1 status and location. 2013;39(1):46-52.

29. Beuvon F, Criscuolo JL, Salmon RJ, Laurent MJBDC. [Radiation-induced neurosarcoma. Clinical, histological and immunohistochemistry aspects]. 1991;78(7):619.

30. Thoennissen N, Schliemann C, Brunnberg U, et al. Chemotherapy in metastatic malignant triton tumor: report on two cases. 2007;18(4):763-767.

31. Yakulis R, Manack L, Murphy AIJAoP, Medicine L. Postradiation malignant triton tumor. A case report and review of the literature. 1996;120(6):541-548.

\section{Figures}



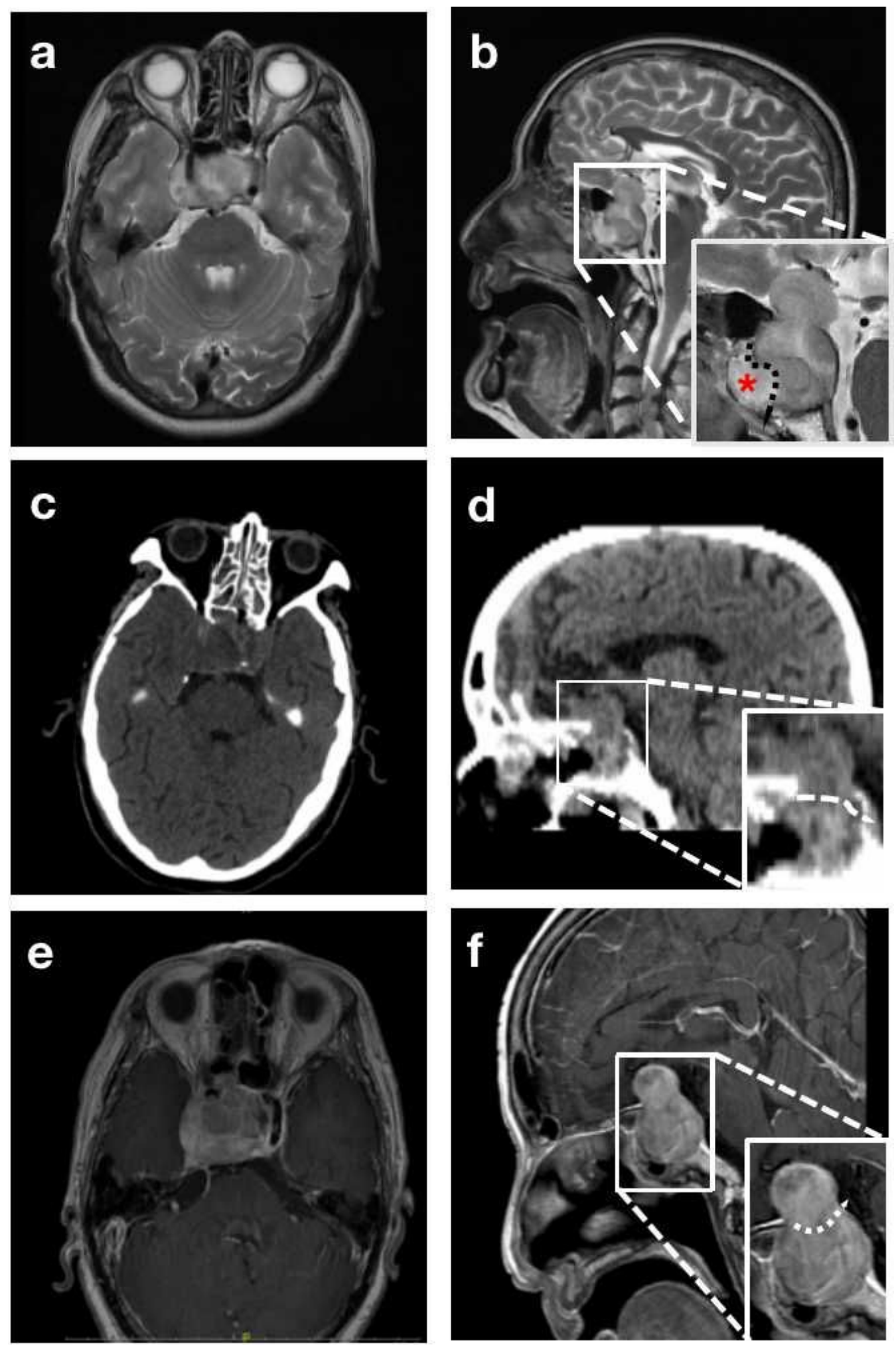

\section{Figure 1}

MRI (a, b, e and $\mathbf{f}$ ) and CT ( $\mathbf{c}$ and $\mathbf{d}$ ) findings in a patient with pituitary adenoma (PA) and concurrent malignant triton tumor (MTT) in sellar area. On 20 days before the operation, axial image (a) and saggittal (b) T2-weighted images revealed that the lesion is consisted of two distinctive components with a clear border. The upper and lower components were histologically diagnosed as pituitary adenoma and MTT (red asterisk), respectively. Four days after the operation, axial (c) and saggittal (d) CT images 
showed that MTT component was totally removed, while residual PA could be seen in suprasellar area. Fifty-six days after the operation, axial (e) and saggittal (f) contrast-enhanced MR images revealed that MTT has recurred.
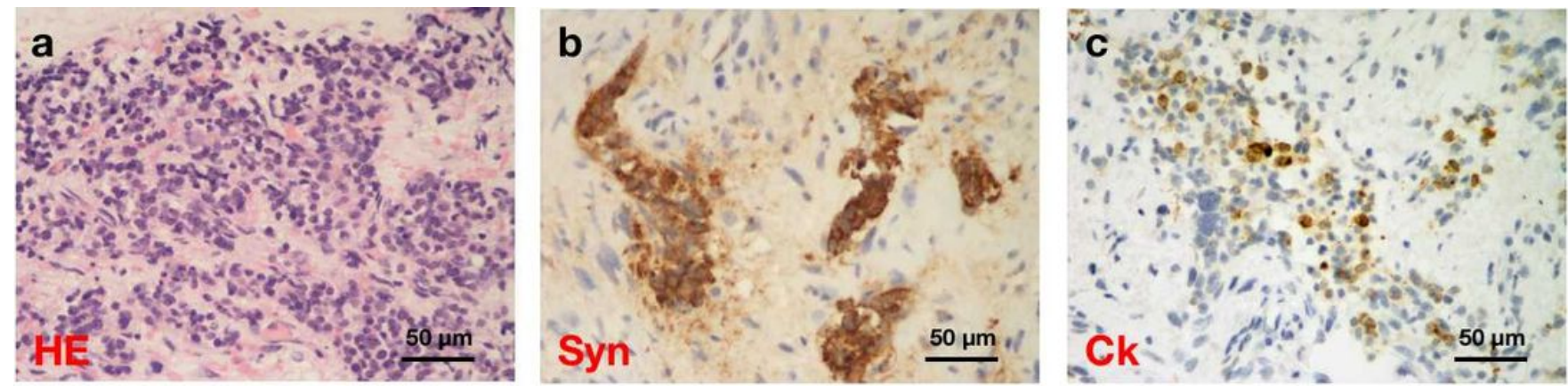

PA
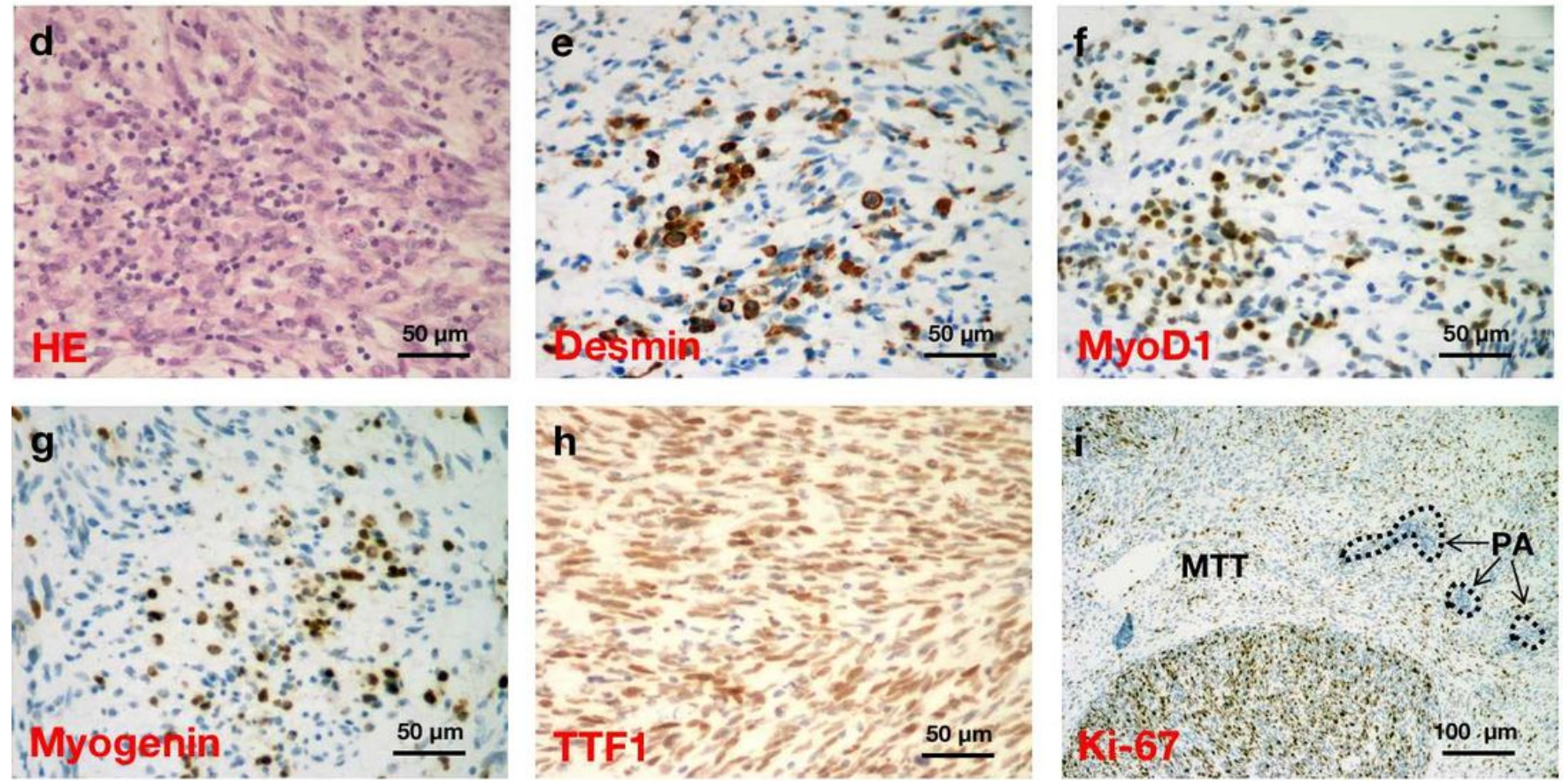

MTT

Figure 2

Hematoxylin and eosin ( $\mathrm{HE}$ ) and immunohistochemical stainings in a patient with pituitary adenoma (PA) and concurrent intracraninal malignant triton tumor (MTT). HE (a) and immunoreactivity of Syn (b) and $\mathrm{Ck}$ (c) supported the diagnosis of PA. Plasmocytoid cells with rhabdomatoid differentiation (d), Desmin (e), Myogenin (f), MyoD1 (g),TTF-1(h) immunoreactivity supported the diagnosis of a MTT. Ki-67 staining (i) was much higher in MTT $(10 \%-60 \%)$ than that in PA (approximately $3 \%$ ). 